\title{
ERRATUM
}

Edgard A. Bontempo e Silva $\cdot$ Shigeaki F. Hasegawa

Kiyomi Ono · Akihiro Sumida $\cdot$ Shigeru Uemura

Toshihiko Hara

\section{Erratum to: Differential photosynthetic characteristics between seedlings and saplings of Abies sachalinensis and Picea glehnif, in the field}

Published online: 26 September 2012

(C) The Ecological Society of Japan 2012

\section{Erratum to: Ecol Res DOI 10.1007/s11284-012-0973-1}

The original article was published with incorrect figures which are corrected as given below:

In Fig. $3 b$, the legends indicating $\alpha$ carotene and $\beta$ carotene were swapped to inverted positions. The original figure should be replaced with the following figure.

The online version of the original article can be found under doi:10.1007/s11284-012-0973-1.

E. A. Bontempo e Silva $(\bowtie) \cdot$ S. F. Hasegawa $\cdot$ K. Ono · A. Sumida $\cdot$ T. Hara

Institute of Low Temperature Science, Hokkaido University,

Kita-19, Nishi-8, Kita-ku, Sapporo 060-0819, Japan

E-mail: silva@lowtem.hokudai.ac.jp

Tel.: + 81-011-7067660

Fax: $+81-011-7067660$

S. Uemura

Forest Research Station, Field Science Center for Northern

Biosphere, Hokkaido University, Nayoro, Japan

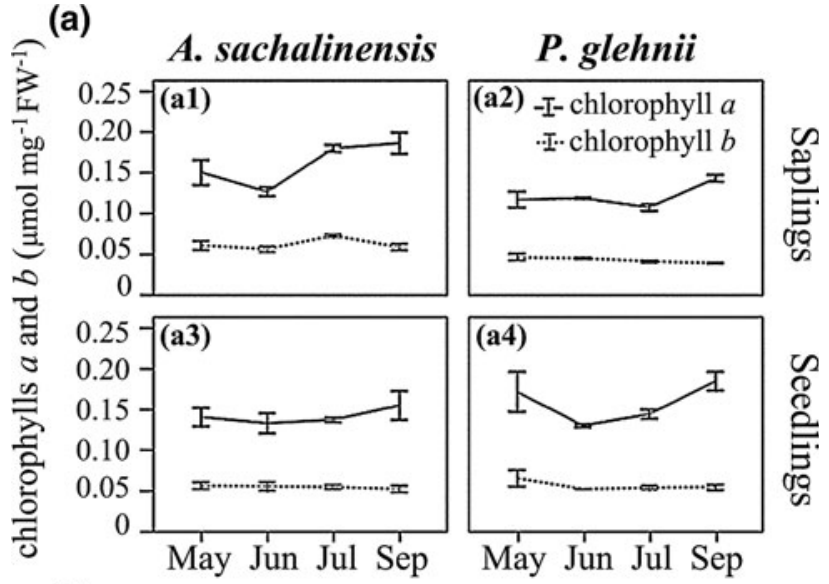

(b)

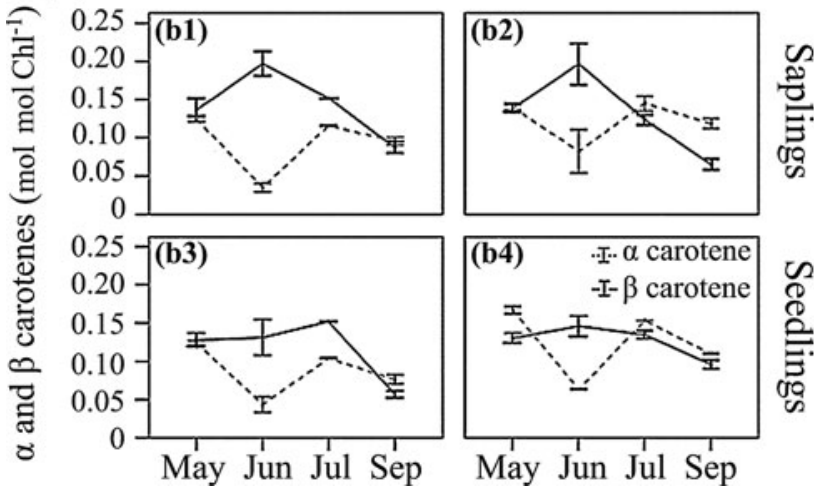


In Figs. 6a, b and 7, the legends indicating seedling and sapling were swapped to inverted positions. The original figures should be replaced by ones given below.

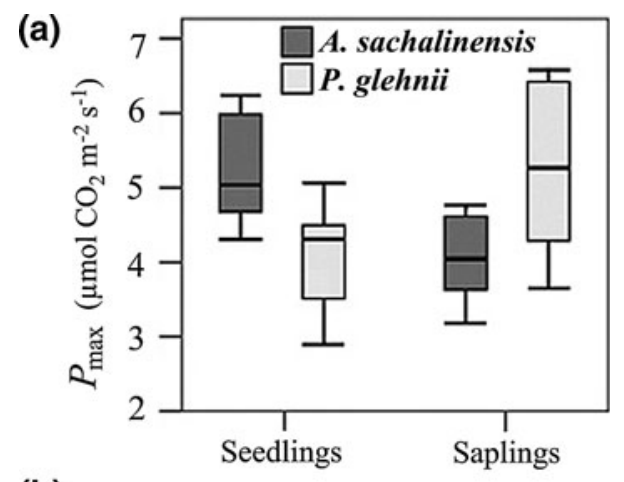

(b)

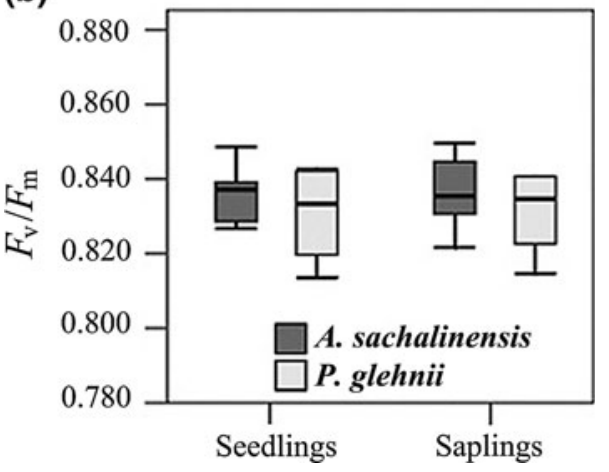

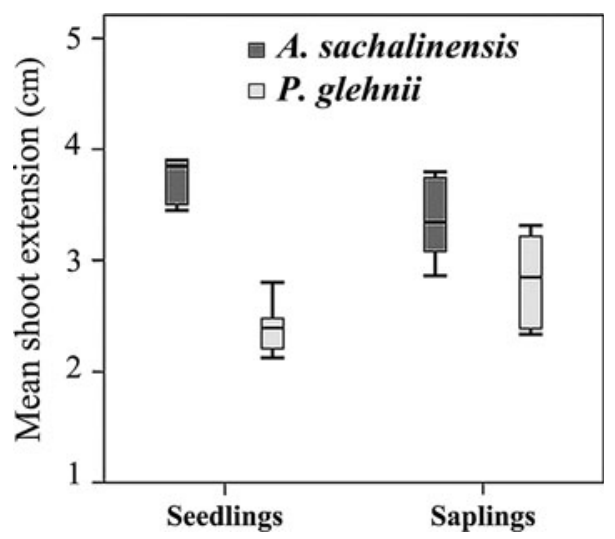

